\title{
Effectiveness of Percutaneous Pedicle Screw Fixation for Traumatic Thoracolumbar Spine Fracture
}

\author{
Gurung $S^{1}$, DC G ${ }^{1}$
}

\begin{abstract}
Introduction: Surgical treatment of thoracolumbar fracture without neurological damage has resulted in better clinical and radiological outcome than conservative treatment. Traditional open approach is associated with extensive paravertebral muscle damage and postoperative morbidity so percutaneous pedicle screw fixation is highly valuable alternatives. Aims: to evaluate the efficacy and outcome of percutaneous pedicle screw fixation in the treatment of traumatic thoracolumbar fracture without neurological deficit. Methods: This study was conducted in Nepalgunj Medical College, Nepalgunj in a time span of one year; total of 40 patients were included and treated with percutaneous pedicle screw fixation and followed up for 6 months. They were evaluated clinically and radiologically. Results: 40 patients with thoracolumbar fractures were managed with percutaneous pedicle screw fixation with a mean operative time of $77.30 \mathrm{~min}$ and intraoperative blood loss was $88.38 \mathrm{ml}$. There was significant improvement in cobb's angle (mean difference 13.92 degree), vertebral body height loss (mean difference 37.7\%) and visual analogue scale (mean difference 3.55) postoperatively. These improvements remained statically significant at 6 months follow up. Conclusion: Percutaneous pedicle screw fixation is safe, valid and effective treatment of thoracolumbar fracture without neurological deficit.
\end{abstract}

Keywords: Cobb's angle, Open spine surgery, Percutaneous pedicle screw fixation, Thoracolumbar fracture, Vertebral body height loss

\author{
Authors: \\ 1. Dr. Sandeep Gurung \\ 2. Dr. Gopalsagar DC \\ ${ }^{1}$ Department of Orthopedics, Nepalgunj Medical College and Teaching Hospital, Nepalgunj, Banke
}

\section{Address for Correspondence:}

Dr. Sandeep Gurung

Department of orthopedics

NepalgunjMedical College and Teaching Hospital

Nepalgunj, Banke

E mail: sgurung848@gmail.com

\section{INTRODUCTION}

Spinal fractures are common injuries associated with multiple trauma's and nearly $80 \%$ to $90 \%$ fractures occur in the thoracic and lumbarspine; ${ }^{(1-2)}$ ranging from compression fractures to flexion distraction ordislocation which resulted on deformity, disability and neurological deficit. ${ }^{3}$ The management ofspinal fractures remains controversial especially if not associated with neurological deficit. Non-surgical treatment mainly braces and or bedrest is associated withkyphosis, prolonged recumbency and its complications and late neurological impairment. ${ }^{4}$ Surgical management has better outcomes. Its advantages arespine stabilization, alignment restoration, and spinal canal decompression. ${ }^{5}$

Surgical management involves placement ofpedicle screw by open technique or percutaneous technique. ${ }^{6}$ The safety and efficacy of open techniquehas been well documented. ${ }^{7}$ however, it has been concerned of some as an aggressive technique for a single level involvement without a neurological deficit. $^{8}$ This is especially because of approach related morbidities such as blood loss, extensive paravertebral muscle dissection, increase risk of infection, and delayed functional recovery. ${ }^{9}$ To minimize these complications percutaneous pedicle screw fixation (PPSF) technique was first introduced by Magerl in $1977 .{ }^{10}$ Compared to open technique percutaneous technique has many advantages such as minimal blood loss, small incision, no paraspinal muscle dissection, reduce postoperative pain and hospitalization; which makes recovery easy and fast. ${ }^{11}$ While the limitations of this approach areinadequate control of reduction and longer fluoroscopy time. ${ }^{12}$ The aim of our study was to evaluate the epidemiology and outcome of thoracolumbar fracture without neurological deficit treated with percutaneous pedicle screw fixation.

\section{METHODS}

This was a prospective, interventional, hospital-based study conducted in Nepalgunj medical college Teaching hospital Nepalgunj in between February 2019 to February 2020. There were 40 patients with thoracolumbar fracture without neurological deficit who had undergone PPSF; was evaluated for 
patient'sdemographic data, mode of injury, fracture type and level, preoperative and postoperative visual analogue scale for back pain, radiological parameters like pre and post-operative comparison of cobbs angle and percentage of vertebral body height reduction,complication's and hospitalization time. Then patients were followed up for three months and six months. At final follow up modifiedMacnab criteria ${ }^{13}$ was used for clinical outcome.

\begin{tabular}{ll} 
CLASSIFICATION & \multicolumn{1}{c}{ CRITERIA } \\
Excellent & $\begin{array}{l}\text { Free of pain } \\
\text { No restriction of mobility } \\
\text { Able to return to normal work and activity }\end{array}$ \\
Good & $\begin{array}{l}\text { Occasional non radicular pain } \\
\text { Relief of presenting symptoms } \\
\text { Able to return to modified work }\end{array}$ \\
\hline Fair & $\begin{array}{l}\text { Some improved functional capacity } \\
\text { Still handicapped and or unemployed }\end{array}$ \\
Poor & $\begin{array}{l}\text { Continuous objective symptoms of root involvement } \\
\text { Additional operative intervention needed at the index } \\
\text { level, irrespective of length of postoperative follow up. }\end{array}$
\end{tabular}

Table I: Modified Macnab outcome criteria

Inclusion criteria are age between 18 to 60 years, single level traumaticthoracolumbar compression fracture without neurological deficit (ASIA $E^{14}$ ), and/orkyphotic angle > 20 degrees and/or loss of vertebral body height $(\mathrm{VBH}) \geq 50 \%$. Exclusion criteria were: age less than 18 years or over 60 years, suspected pathological fractures, distraction and rotational thoracolumbar fracture and the presence of neurological deficit.

\section{Operative Technique}

The patient was under general anesthesia in the prone position with the abdomen uncovered and all pressure points are padded to prevent peripheral nerve palsies and skin breakdown. Identification of the entry point was made with fluoroscopic control. The patient is then prepared and draped in the normal sterile fashion an incision of approximately 2 $\mathrm{cm}$ was made in the skin, slightly lateral to the pedicle entry point. An underlying longitudinal fasciotomy is performed with monopolar electrocautery to allow for the easier passage of instruments. An entry awl is used to advance through the musculature and then positioned onto the junction of the lateral facet joint and transverse process and tapped with mallet onto the pedicle using AP and lateral fluoroscopy. Then pedicle probe is used and angled at appropriate directions into the pedicle and vertebral body using fluoroscopy. A ball tip probe is used to palpate 5 surfaces (inferior, medial, lateral, superior and floor) to check their integrity. An appropriately sized screw is then inserted and assessed with standard fluoroscopy. The exact same steps are repeated at other level and a connective bar of appropriate length was placed and the bolt was tightened. A distraction tool was used. The wounds were flushed and sutured in layers without drainage. Postoperatively, prophylactic antibiotic treatment was administered. The patient was allowed to stand after 24 hours and return to daily activities within two weeks.

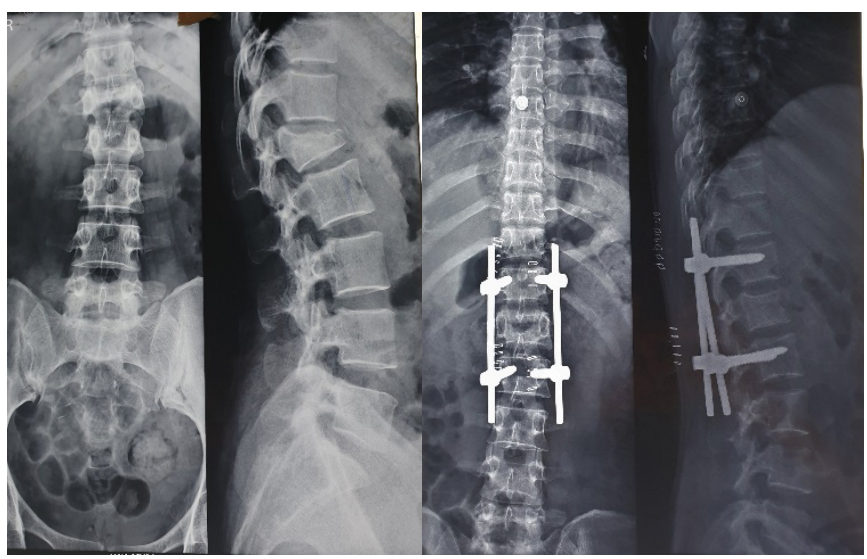

Figure 1: Pre and post op radiograph

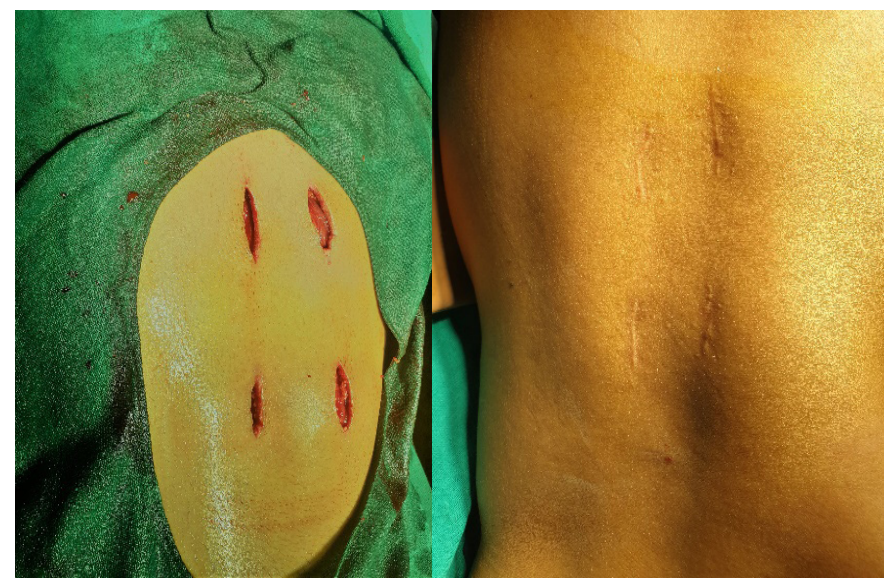

Figure 2: Surgical incision and post surgical scar

\section{RESULTS}

A total of 21 men and 19 women with a mean age of 36.15 years were operated with PPSF technique. Fall from height were the mode of injury in $65 \%$, followed by road traffic accident in $35 \%$ of patients. The mean operative time was $77.30 \mathrm{~min}$. intraoperative blood loss averaged $88.38 \mathrm{ml}$. And averaged duration of hospitalization was 6.43 days.

Comparison of pre and post-operative imaging showed significant correction in the kyphotic angle $(p=0.001)$ with a mean difference of $13.92^{\circ}$ which represents an improvement of about $61 \%$. Therewas also significant improvement in vertebral body height $(p=0.001)$ with a mean difference of $37.7 \%$ which is about $67 \%$ correction post operatively.At the 3month follow up mean cobb's angle and vertebral body height were $10.28^{\circ}$ and $18.65 \%$ respectively. At $6 \mathrm{mth}$ post operations average cobb's angle was $10.48^{\circ}$ and vertebral body height was $21.13 \%$. Pre operatively back pain score on VAS was 6.73; Post operatively the patient reported an improvement in pain scores with a mean difference of 3.55 in VAS $(p=0.001)$. At $3 \mathrm{mth}$ and $6 \mathrm{mth}$ follow up back pain scores on VAS was 1.13 and 0.83 respectively. Overall patient satisfaction at final follow up using modified Macnab criteria was $90 \%$ (35\% excellent, 55\% 
good) and fair in $10 \%$.

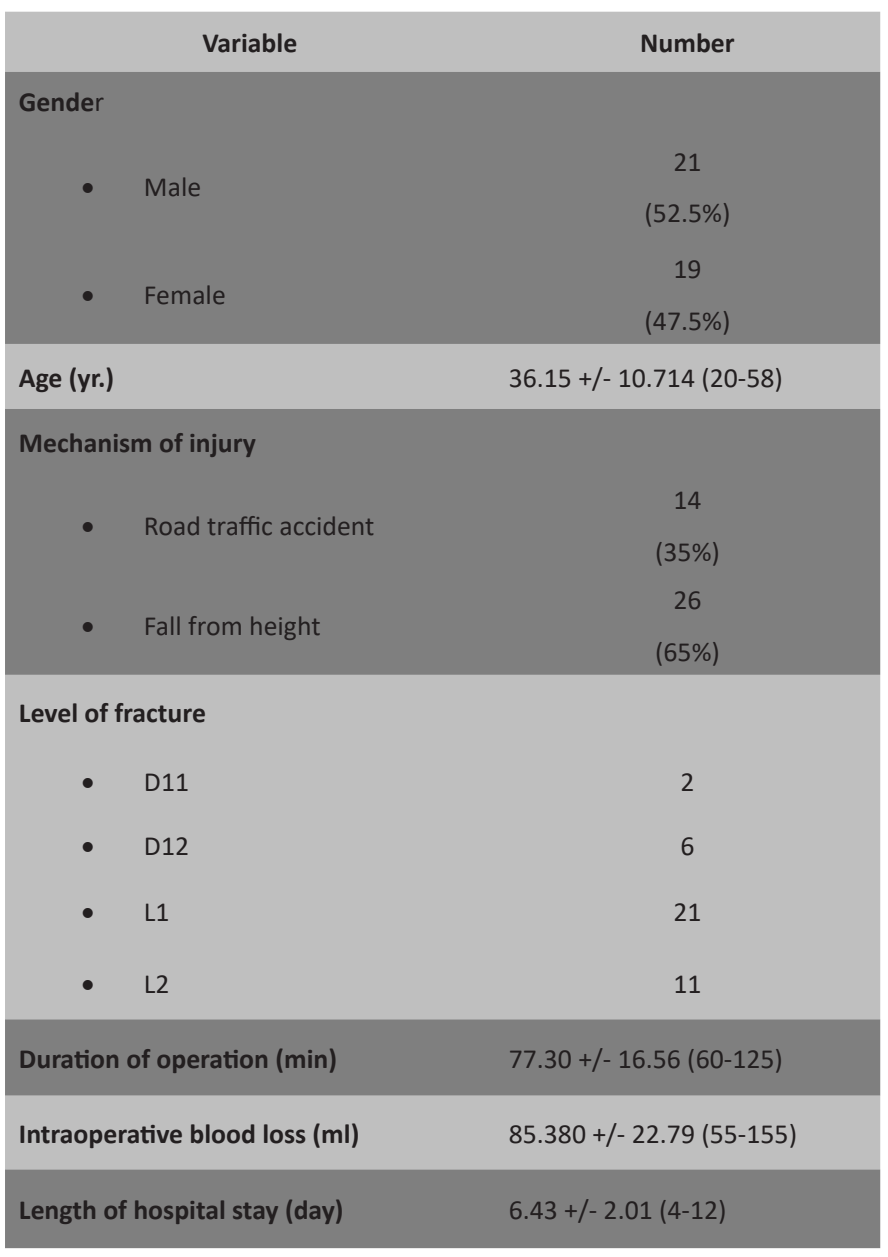

Table II: Demographic and technical data of study populations

\begin{tabular}{|c|c|c|c|c|}
\hline & Preoperative & postoperative & 3mth. FU & 6mth. FU \\
\hline Cobb's angle( $\left.{ }^{\circ}\right)$ & $\begin{array}{c}22.78+/-4.57 \\
(16-32)\end{array}$ & $\begin{array}{c}8.85+/-2.08 \\
(5-14)\end{array}$ & $\begin{array}{l}10.28+/- \\
1.79 \\
(8-15)\end{array}$ & $\begin{array}{c}10.48+/-1.78 \\
(8-15)\end{array}$ \\
\hline $\begin{array}{l}\text { Reduction of } \\
\text { vertebral body } \\
\text { height (\%) }\end{array}$ & $\begin{array}{c}55.93+/-7.83 \\
(44-76)\end{array}$ & $\begin{array}{c}18.23+/-6.27 \\
(7-29)\end{array}$ & $\begin{array}{l}18.65+/- \\
5.82 \\
\quad(10-29)\end{array}$ & $\begin{array}{c}21.13+/-4.78 \\
(12-29)\end{array}$ \\
\hline VAS score & $\begin{array}{c}6.73+/-1.19 \\
(5-9)\end{array}$ & $\begin{array}{c}3.18+/-0.81 \\
(2-5)\end{array}$ & $\begin{array}{c}1.13+/-0.40 \\
(0-2)\end{array}$ & $\begin{array}{l}0.83+/-0.44 \\
(0-2)\end{array}$ \\
\hline
\end{tabular}

Table III: Imaging evaluations and VAS score results before and after surgery

\section{DISCUSSION}

Pedicle screw fixation is a reliable method for the stabilization of thoracolumbar fractures. However traditional open posterior approach is associated with significant amount of blood loss during surgery, extensive muscle dissection and denervation, increased post-operative pain, longer hospital stay and possible functional impairment. ${ }^{15}$ On the other hand,PPSF, first introduced by Magerl in $1977^{16}$ have been developed to minimize the open approach related drawbacks and complications. Kim et a ${ }^{17}$ demonstrated thatpercutaneous pedicle fixation causes minimal collateral damage to the muscle than open fixation technique. The disadvantage of PPSF is heavy reliance on imaging with a lack of tactile feedback leading to more radiation exposure to surgeon and patient. Another obvious disadvantage is lack of bony fusion; which would add a mechanical stability provided by open procedure, however the necessity of fusion had been a subject of debate. ${ }^{18-20}$ Toyone et al ${ }^{18}$, Sanderson et $\mathrm{al}^{19}$ and Wang et al ${ }^{20}$ concluded on theirstudies done separately that short segment fixation without fusion could achieve satisfactory result for thoracolumbar fracture.

The average operative timewas 77.30 min which is comparable to study done by $\mathrm{Ni}$ et $\mathrm{al}^{21}$ who reported an average operative time of $70 \mathrm{~min}$ and Silva et al ${ }^{22}$ reported a mean operative time of $81 \mathrm{~min}$. while the mean blood loss in our study was 85.38 $\mathrm{ml}$ which is consistent with the study done by Silva et al ${ }^{22}$ who reported $85 \mathrm{ml}$ mean blood loss. Compared to open group operative time and blood loss were significantly lower in PPSF, with a mean operative time of $153 \mathrm{~min}$ and blood loss was 828 $\mathrm{ml}$ in open pedicle fixation surgery as reported by Verlaan et al. ${ }^{23}$ Most of our patents showed a significant improvement in back pain according to VAS with a pain reduction from 6.73 preoperatively to 3.18 postoperatively and 0.83 at final follow up. Wang et $\mathrm{al}^{24}$ reported a mean postoperative VAS score of 2.2 for open group and 1.5 for PPSF group which resulted on early mobilization, short recovery time and reduced hospital stay for PPSF group.

A significant improvement in kyphosis angle and vertebral body height had been observed postoperatively and subsequent follow up. The average postoperative cobb's angle of kyphosis was $8.85^{\circ}$ and final follow up was $10.48^{\circ}$ which is comparable to the results reported by $\mathrm{Ni}$ W et al ${ }^{26}$ who observed final mean cobb's angle of $8.9^{\circ}$, and the results published by Elsawaf et a ${ }^{25}$ who showed a $71 \%$ improvement in the cobb's angle postoperatively. Siebenga et al ${ }^{5}$ demonstrated an $8.2^{\circ}$ mean improvement of kyphosis in patient undergoing surgical treatment compared to $4.1^{\circ}$ worsening of kyphosis patient treated conservatively demonstrating clear advantage of surgical treatment over conservative treatment in thoracolumbar fracture. The percentage of mean reduction vertebral body height postoperatively was $18.23 \%$ and $21.13 \%$ at final follow up which is comparable to study done by Silva et $\mathrm{a}^{22}$ who reported improvement of $29.5 \%$ postoperatively. Vanek et al (2014) $)^{26}$, Wang et al $(2014)^{24}$ concluded that there was no significant difference between open group and PPSF group regarding kyphosis angle and restoration of vertebral body height.

For clinical outcome we used modified Macnab criteria with patient satisfaction rate of $90 \%$ ( $55 \%$ excellent, $35 \%$ good) which is comparable with the results published by Hasanein et $\mathrm{a}^{27}$ with a reported satisfaction rate of $93 \%$ and Wang et a ${ }^{28}$ with an overall patient satisfaction rate of $88 \%$. 


\section{LIMITATIONS}

The limitations of our study were lack of comparison between PPSF and open surgery, small sample size and short follow up period.

\section{CONCLUSION}

Based on our study we have concluded that PPSF is a safe, valid and reliable alternative to open surgery in the management of thoracolumbar fracture without neurological deficit. Our study demonstrated that PPSF is superior in terms of postoperative pain, blood loss, hospital stay, incision scar and return to activities of daily living in comparison to open surgery procedure.

\section{REFERENCES}

1. Hsu JM, Joseph T, Ellis AM. Thoracolumbar fracture in blunt trauma patients: guidelines for diagnosis and imaging. Injury 2003;34:426-33.

2. Samelson EJ, Hannan MT, Zhang $\mathrm{Y}$, et al. Incidence and risk factors for vertebral fracture in women and men: 25-year follow-up results from the population-based Framingham study. J Bone Miner Res 2006;21: 1207-14.

3. Magerl F, Aebi M, Gertzbein SD, Harms J, Nazarian S. A comprehensive classification of thoracic and lumbar injuries. Eur Spine J. 1994;3(4):184-201. doi: 10.1007/BF02221591. PMID: 7866834.

4. Domenicucci M, Preite R, Ramieri A, Ciappetta P, Delfini R, Romanini L. Thoracolumbar fractures without neurosurgical involvement: surgical or conservative treatment? J Neurosurg Sci. 1996;40(1):1-10.

5. Siebenga J, Leferink VJ, Segers MJ, Elzinga MJ, Bakker FC, Haarman HJ, et al. Treatment of traumatic thoracolumbar spine fractures: a multicenter prospective randomized study of operative versus nonsurgical treatment. Spine (Phila Pa 1976). 2006;31(25):2881-90.

6. Oner FC, Wood KB, Smith JS, Shaffrey Cl (2010) Therapeutic decision making in thoracolumbar spine trauma. Spine (Phila Pa 1976) 35: S235-244.

7. Wild $\mathrm{MH}$, Glees M, Plieschnegger C, Wenda K. Five-year follow-up examination after purely minimally invasive posterior stabilization of thoracolumbar fractures: a comparison of minimally invasive percutaneously and conventionally open treated patients. Arch Orthop Trauma Surg. 2007 Jul;127(5):335-43.

8. Palmisani M, Gasbarrini A, Brodano GB, et al. Minimally invasive percutaneous fixation in the treatment of thoracic and lumbar spine fractures. Eur Spine J 2009; 18 suppl 1:714.

9. Weber BR, Grob D, Dvorák J, Müntener M. Posterior surgical approach to the lumbar spine and its effect on the multifidus muscle. Spine (Phila Pa 1976). 1997 Aug 1;22(15):1765-72.

10. Magerl FP. Stabilization of the lower thoracic and lumbar spine with external skeletal fixation. Clin Orthop Relat Res. 1984;(189):125-41.

11. Smith JS, Ogden AT, Fessler RG. Minimally invasive posterior thoracic fusion. Neurosurg Focus 2008;25:E9.

12. Zairi F, Court C, Tropiano P, Charles YP, Tonetti J, Fuentes S, Litrico S, Deramond H, Beaurain J, Orcel P, Delecrin J, Aebi $M$, Assaker R. Minimally invasive management of thoracolumbar fractures: combined percutaneous fixation and balloon kyphoplasty. Orthop Traumatol Surg Res 2012; 98: S105-S111.

13. Macnab I. Negative disc exploration. An analysis of the causes of nerve-root involvement in sixty-eight patients. J Bone Joint Surg Am. 1971 Jul;53(5):891-903.

14. Jr, Frederick M Maynard et al. "International Standards For Neurological And Functional Classification Of Spinal Cord Injury". Spinal Cord 35.5 (1997): 266-274.

15. Grass R, Biewener A, Dickopf A, Rammelt S, Heineck J, Zwipp $\mathrm{H}$. Perkutanedorsale versus offene Instrumentation beiFrakturen des thorakolumbalenUbergangs. Eine vergleich endeprospektiveUntersuchung [Percutaneous dorsal versus open instrumentation for fractures of the thoracolumbar border. A comparative, prospective study]. Unfallchirurg. 2006 Apr;109(4):297-305.

16. Magerl FP. Stabilization of the lower thoracic and lumbar spine with external skeletal fixation. Clin Orthop Relat Res. 1984 Oct;(189):125-41.

17. Kim DY, Lee SH, Chung SK, Lee HY. Comparison of multifidus muscle atrophy and trunk extension muscle strength: percutaneous versus open pedicle screw fixation.Spine (Phila Pa 1976). 2005;30(1):123-9.

18. Toyone T, Ozawa T, Inada K, et al. Short-segment fixation without fusion for thoracolumbar burst fractures with neurological deficit can preserve thoracolumbar motion without resulting in post-traumatic disc degeneration: a 10year follow-up study. Spine (Phila Pa 1976) 2013;38:148290.

19. Sanderson PL, Fraser RD, Hall DJ, et al. Short segment fixation of thoracolumbar burst fractures without fusion. Eur Spine J 1999; 8:495-500.

20. Wang ST, Ma HL, Liu CL, et al. Is fusion necessary for surgically treated burst fractures the thoracolumbar and lumbar spine?: a prospective, randomized study. Spine (Phila Pa 1976) 2006; 31:2646-52.

21. Ni WF, Huang $Y X, C$ Chi $Y L, X u H Z$, Lin $Y$, Wang $X Y$, Huang QS, Mao FM. Percutaneous pedicle screw fixation for neurologic intact thoracolumbar burst fractures. J Spinal Disord Tech. 2010 Dec;23(8):530-7. doi: 10.1097/BSD.0b013e3181c72d4c. PMID: 21131801.

22. Silva, Luís Miguel Pinheiro da, et al. "Percutaneous pedicle fixation of thoracolumbar vertebral fractures without neurological deficits." Coluna/Columna 12.3 (2013): 238241.

23. Verlaan JJ, Diekerhof $\mathrm{CH}$, Buskens E, van der Tweel I, Verbout 
AJ, Dhert WJ, et al. Surgical treatment of traumatic fractures of the thoracic and lumbar spine: a systematic review of the literature on techniques, complications, and outcome. Spine (Phila Pa 1976). 2004;29(7):803-14.

24. Wang H, Zhou Y, Li C, Liu J, Xiang L. Comparison of Open Versus Percutaneous Pedicle Screw Fixation Using the Sextant System in the Treatment of Traumatic Thoracolumbar Fractures. Clin Spine Surg. 2017 Apr;30(3):E239-E246.

25. Elsawaf A., Al-Qazaz M.Comparison of Percutaneous and Open Posterior Spinal Fixation in Thoracolumbar Fractures. Egyptian journal of neurosurgery. $2016 ; 31(2): 125-30$.

26. Vanek $\mathrm{P}$, Bradac $\mathrm{O}$, Konopkova R, de Lacy $\mathrm{P}$, Lacman J, Benes V. Treatment of thoracolumbar trauma by short-segment percutaneous transpedicular screw instrumentation: prospective comparative study with a minimum 2-year follow-up. J Neurosurg Spine. 2014 Feb;20(2):150-6.

27. Hasanein M., Elkazaz, M. Assessment of Percutaneous Pedicle Screw Fixation in Management of Traumatic Thoracolumbar Spine Fractures; Local Study at Suez Canal University Hospital. Egyptian Spine Journal, 2017; 22(1): 3240.

28. Wang HW, Li CQ, Zhou Y, Zhang ZF, Wang J, Chu TW. Percutaneous pedicle screw fixation through the pedicle of fractured vertebra in the treatment of type A thoracolumbar fractures using Sextant system: an analysis of 38 cases. Chin J Traumatol. 2010 Jun 1;13(3):137-45. 